\title{
Effect of settlement of foundations on the failure risk of the bottom of cylindrical steel vertical tanks for liquids
}

https://doi.org/10.2478/sgem-2019-0017

received February 27, 2019; accepted June 5, 2019.

\begin{abstract}
Different types of foundations are used in steel, above-ground cylindrical storage tanks for liquids. If a sand-gravel foundation is used under the entire bottom of the tank or only in the central part of the tank, settlement can be expected, and it increases after many years of operation. The paper presents the typical kinds and types of soil settlements under the bottoms of the tanks, in which different types of foundations were used. Numerical analyses of the effect of the soil settlement on the state of deformations and stresses in steel sheets of the bottom under one of the real tanks, in which different types of foundations and different cases of settlement were assumed. The results of numerical analyses indicated the possibility of evaluating the state of the soil settlement and bottom sheet deformations on the basis of simple measurements of deformations of the lower part of the tank cylinder. These measurements can be very useful in assessing the possible risk of failure of the tank bottom during each period of its operation, as measurements of settlement of the bottom of a filled tank are not feasible in practice. It has been proposed that in each steel tank, the deformation of the cylinder's sheets should be measured even before the beginning of exploitation, and that in subsequent periodical measurements, the influence of the soil settlement under the tank on the state of the cylinder deformation and bottom's strain should be assessed more accurately.
\end{abstract}

Keywords: Steel tank, soil settlement, tank deformations, plastic deformations, failure risk.

\footnotetext{
*Corresponding author: Eugeniusz Hotala, Faculty of Civil Engineering, Wrocław University of Science and Technology, Wroctaw, Poland, E-mail: eugeniusz.hotala@pwr.edu.pl Rajmund Ignatowicz: Faculty of Civil Engineering, Wroctaw University of Science and Technology, Wroctaw, Poland
}

\section{Introduction}

Vertical cylindrical steel tanks for the storage of liquids use different types of foundations. In such tanks, sometimes ground-layered foundations are used, and much more often, ring-shaped reinforced concrete foundations with compacted gravel-sand substrate inside these rings. During long-term operation of the tanks, the soil under the steel bottom of the tank undergoes permanent deformations in the form of vertical non-uniform settlement. This settlement can have different causes, but in each case, affects the state of stress and deformation in the bottom plates and at the lower edge of the cylindrical shell. There are known cases of steel tank bottom failures, in which excessive or non-uniform deformation of the sand foundation inside the ring foundation [1], [2] occurred. Advanced analyses of the influence of the soil settlement of tank bottoms on the state of their and shells' stresses are included in the doctoral thesis [3].

The paper presents the analyses of the support of chosen steel tanks on ring foundations, in which the bottom plates may crack due to large and non-uniform settlement foundations inside the reinforced concrete rings.

\section{Analyzed types of steel tank foundations}

The analysis of emergency risk, presented in this article, will concern three types of foundations used under the bottoms of steel cylindrical tanks with vertical axis. The first type is the sand-gravel foundation, which is used more and more rarely. This type, marked in Fig. 1 as type A, consists of properly selected and compacted layers of sand, bitumen, insulation and coarse gravel. A typical arrangement of these layers is presented, among others, in Fig. 1 of EN 14015:2004 [7]. 
The most commonly used solution for the foundation construction under the analyzed steel tanks is reinforced concrete ring foundation under the cylindrical tank shell and sand-gravel foundation inside the ring foundation on which the steel sheet of the tank bottom is based. This type of analyzed foundation is marked as type B and shown schematically in Fig. 1.

Due to the fact that in the case of B-type foundation, there may occur a large difference in the settlement values of the external edge of the bottom (rigid reinforced concrete foundation) and the central part (flexible sand foundation), the C-type foundation is being increasingly used (Fig. 1), in which the entire tank is located on a sand foundation, and the reinforced concrete ring foundation is used to stabilize the soil within (inside) it under the bottom and to anchor the tank shell.

\section{Chosen causes of deformation of sand-gravel foundations under the bottoms of tanks}

The settlement of vertical axis cylindrical steel tanks for liquids have various causes. The main reason is the gradual, natural consolidation of the ground under the steel bottom of the tank, which occurs after long, intensive use, even in the case of homogeneous soil structure. In this case, the entire tank will settle uniformly or in the form of the trough (Fig. 2a). If there are local lenses of weak soil under the bottom of the tank, it is also possible to settle in the form of circumferential troughs (Fig. 2b) near or at some distance from the tank shell or locally in the area of the shell on part of its perimeter (Fig. 2c).

Another reason for the formation of peripheral (Fig. 2b) or local (Fig. 2c) ground trough under tank's bottom of the tank foundation is the penetration of rainwater under its bottom (Fig. 3), which occurs quite often in real tanks. Such penetration of rainwater under the steel bottom can be facilitated by the type of foundation (Type $\mathrm{C}$ in Fig. 3), improper slope around the tank (Type A in Fig. 3a) or structural errors of the ring foundation and its sealing (Type B in Fig. 3b). Effects of loosening of the soil at the ring foundation on deformations and emergency risk of tank bottoms in the case of using the type B of foundation (Fig. 1b) are shown in [4].

The penetration of rainwater under the bottom of the tanks (Fig. 3) is generally underestimated in practice, but it carries a serious risk of large local deformations of the bottoms of the tanks, which may result in their emergency

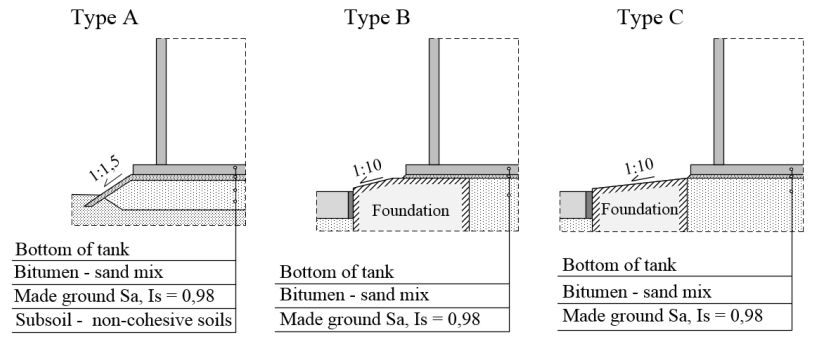

Figure 1: Analyzed types of tank foundations: Type A, Type B, Type C.

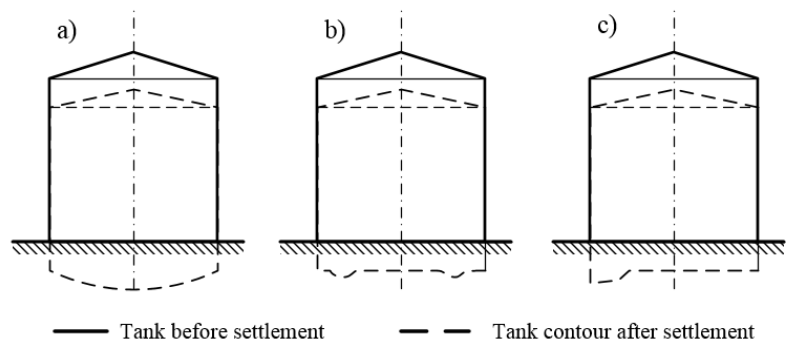

Figure 2: Chosen cases of settlement of cylindrical tanks [3]: a) in the form of a trough, b) circumferential trough near or far from the shell, c) local trough near the shell
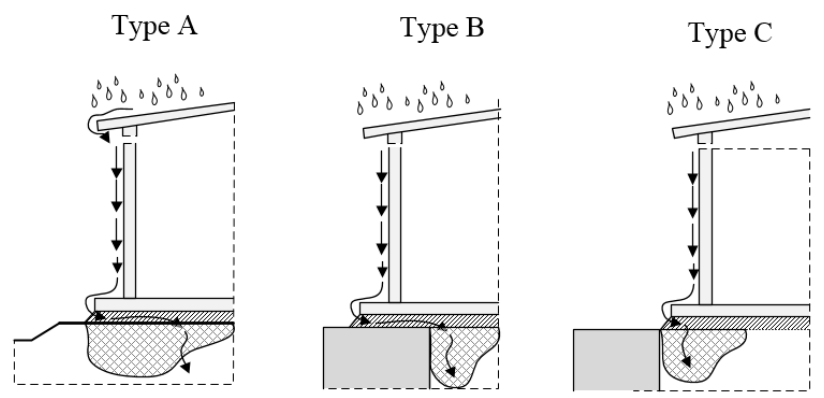

Figure 3: Penetration of rainwater under the bottom of tanks: Type A, Type B, Type C.

risk, [4] if for many years of operation, rainwater loosens the soil surface under their bottoms. The state of deformation of the bottom of steel tanks during operation is difficult to determine, because detailed geodetic measurements of the bottoms during the filled tank are practically impossible to perform. The original method of calculation of vertical deformations of the tank bottom on the basis of radial deformations of the lower part of the cylindrical shell is presented in paper [1], and a similar and practically used method of assessment of deformations of the tank bottom is also presented in paper [4]. 

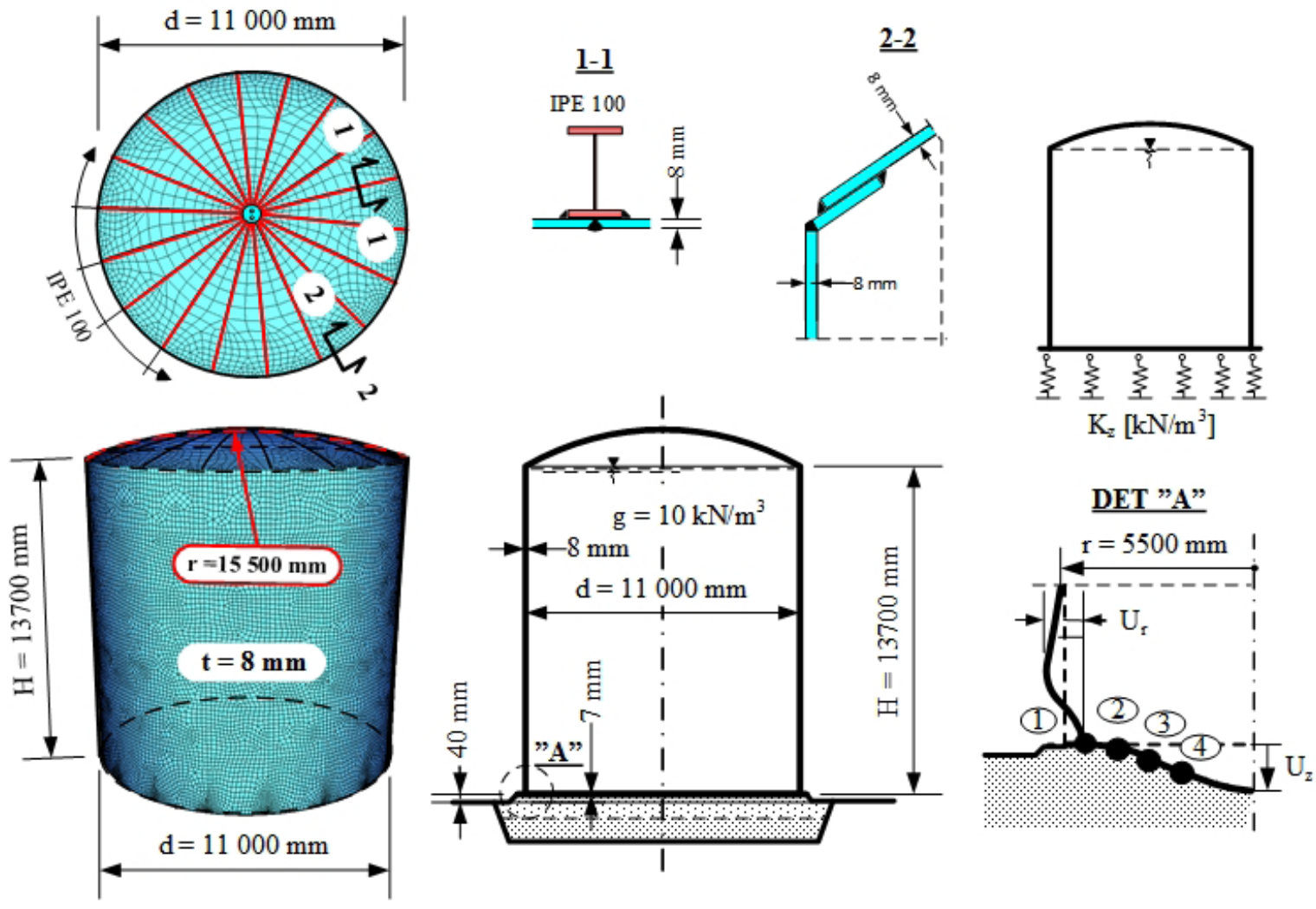

Figure 4: Geometry of the analyzed steel tank on a type A foundation and vertical deformations of the bottom plates $u_{z}$ and radial deformations of the cylinder shell $u_{r}$.

\section{Deformation of the bottom and shell wall of the steel tank as a result of the soil settlements}

In case of using one of the 3 types of foundations (Fig. 1), vertical ground settlement causing vertical deformation of the bottom plates under the bottom of the tank (Fig. 2), radial deformation of the lower part of the tank shell wall will occur. Numerical analyses of these accompanying deformations were carried out on the example of a real tank with the geometry as shown in Fig. 4, designed for storage of industrial wastewater with a volumetric weight of $y=10.0 \mathrm{kN} / \mathrm{m} 3$. This picture shows an example of a sand foundation under the tank according to Fig. 1a (Type A). Numerical analyses of the same tank were also carried out for other types of the sand foundations that is, of Type B and Type C (Fig. 1).

Advanced numerical analyses were performed with SOFiSTiK [8], in which the stiffness $K_{z}$ of the ground was modelled in such a way as to obtain more and more vertical dents $u_{z}$ of the bottom plates with a full tank. The whole tank was made of steel with yield strength $f_{\mathrm{y}}=235 \mathrm{~N} / \mathrm{mm}^{2}$. The numerical model was created from bar elements and shell elements. The tank structure has been mapped with 4 nodal shell elements, while maintaining alignment with the central surface of the coating. The density of finite elements (FEA) was determined on the basis of the so-called solution convergence analysis, and as a criterion, it was assumed that the difference of displacement values at points to be analyzed between successive models with increasingly lower grid density did not exceed $2 \%$. Finally, 205159 QUAD type of shell elements and 432 bar-elements (tank roof) were obtained, and the number of equations was 267,348,609. The one-parameter Winkler's model was assumed for the soil. Calculations were carried out according to non-linear analysis with consideration of material and geometric non-linearities with updating of stiffness matrix and structure geometry after each step of calculations.

Validation of the author's numerical model used in the article (SOFiSTiK [8]) was carried out by performing the numerical analyses of the tank, which was subject to numerical analyses by NASTRAN software and subjected to classical theoretical analyses in the paper [3]. The tanks had a capacity $\mathrm{V}=1350 \mathrm{~m}^{3}$, diameter $\mathrm{d}=12000 \mathrm{~mm}$ and height $\mathrm{H}=12000 \mathrm{~mm}$. It was placed on Winkler's soil with stiffness $\mathrm{K}_{\mathrm{z}}=500 \mathrm{MN} / \mathrm{m}^{3}$. Very similar results of 
displacement and stresses in the shell and tank bottom were obtained, and the differences did not exceed $5 \% \div 2 \%$. Vertical deformations of the bottom plate of the same tank, based on the foundation type B (Fig. 1) are shown in fig. 5, and when using the foundation type $\mathrm{C}$ in Fig. 6 . In the case of foundation of type $\mathrm{C}$, the loosening of the soil at the ring foundation $350 \mathrm{~mm}$ wide was taken into account.

The results of numerical analyses allowed to determine the relationship between vertical displacements $u_{z}$ of tank bottoms and radial displacements $u_{r}$ of their shells, taking into account all three types of foundations (A, B and C) and with the assumption of elastic-plastic model of steel. The stress-strain relationship for structural steel consisted of a linear and perfectly plastic region: $\mathrm{f}_{\mathrm{y}}=235 \mathrm{MPa}, \mathrm{e}_{\mathrm{y}}=$ $0.1119 \%$. These relationships for the foundation of type A and $B$ are presented in Fig. 7; other cases will be analyzed in point 5 (Fig. 8, Fig. 9). These relationships are of great practical importance, because on the basis of quite easy measurements of $u_{\mathrm{r}}$ deformations of the lower part of the shell, it is possible to estimate the deformations $u_{z}$ of the bottom plates, caused by different types of soil settlements (Fig. 2).

In the case of foundation type A, the deformations of the bottom $u_{\mathrm{z}}$ do not have a significant influence on the value of radial deformations of the shell $u_{r}$ (Fig. 7) if the soil is of uniform stiffness $K_{z}$. In case of B-type foundation, there is a clear relationship between these deformations, which allows to assess the vertical deformations of the bottom plates on the basis of the measured radial deformations $u_{\mathrm{r}}$ of the shell.

\section{Failure risk of the bottom of the tank due to excessive deformation of the soil}

Deformations of the bottom and shell of the tank are accompanied by bending stresses in bottom plates. In the case of the B-type foundation and complete loosening of the soil on a certain width $a$ and in the immediate vicinity of the concrete foundation (Fig. 8), the highest stresses occur at the point no. 2 on the inner edge of the ring foundation, which is also to be found in [5].

In the case under consideration (Fig. 5, Fig. 8), local settlement of the soil over width $a=1.0 \mathrm{~m}$, resulting in vertical deformations of the bottom plate of $u_{z}=33.7 \mathrm{~mm}$ led to the plasticization of the bottom plate at point no. 2. The process of plasticization of the bottom plate with variable $u_{z}$, deformations caused by changes in the filling
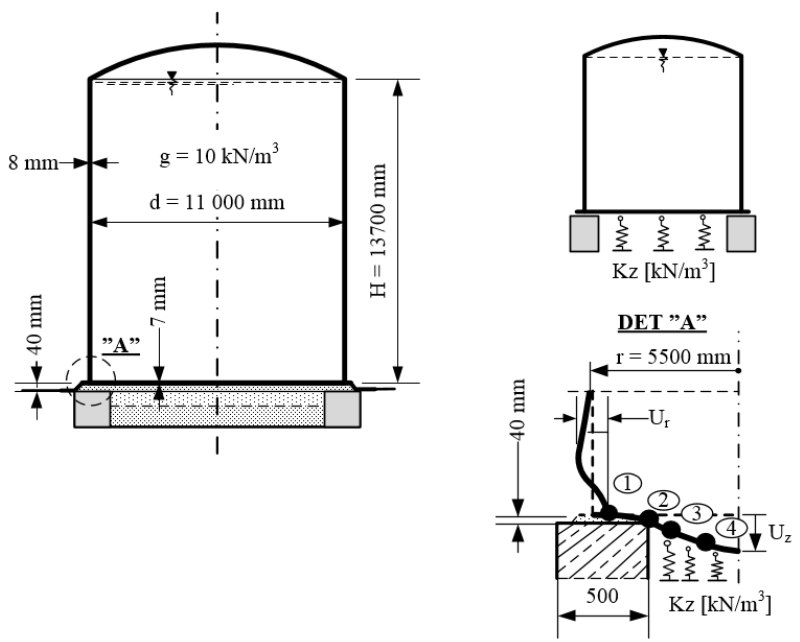

Figure 5: Geometry of the analyzed steel tank on a type B foundation and vertical deformations of the bottom plates $u_{z}$ and radial deformations $u_{r}$ of the shell wall.
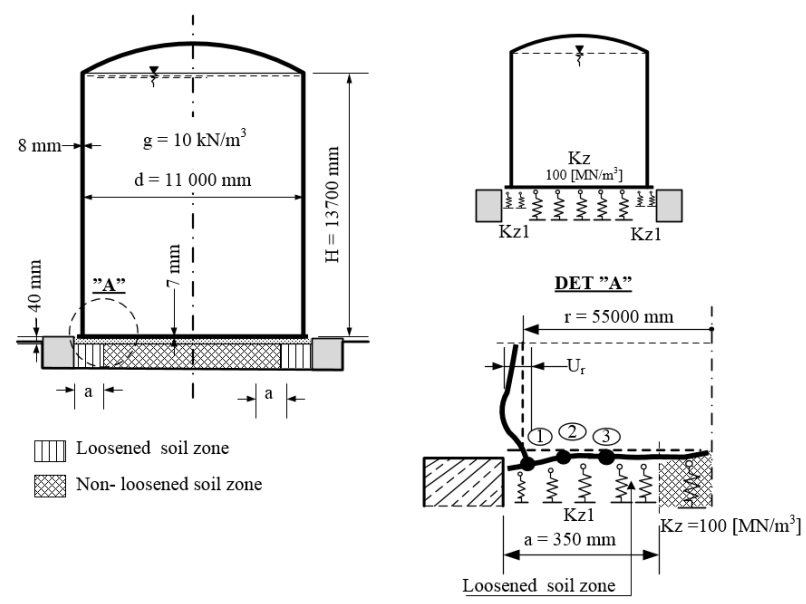

Figure 6: Geometry of the analyzed steel tank on a type $C$ foundation with loosened soil zone $\left(K_{z 1}\right)$ and deformations $u_{z}$ of the bottom plate and $u_{\mathrm{r}}$ of the shell.

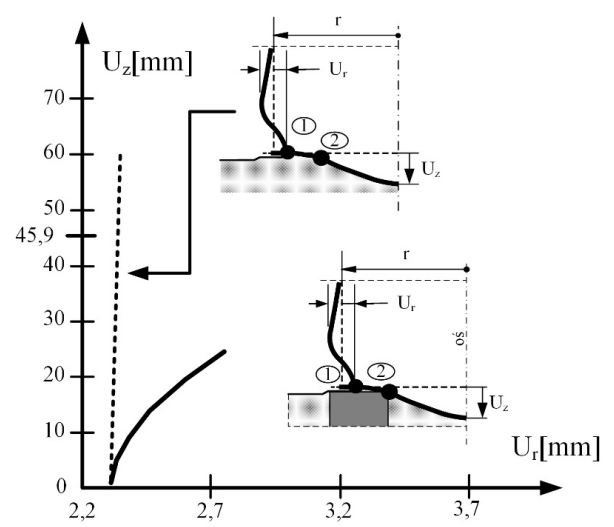

Figure 7: Comparison of vertical deformations $u_{z}$ of tank bottom plates and radial deformations $u_{\mathrm{r}}$ at the point No. 2 for type $A$ and type B foundations of uniform stiffness $K_{z}$ (Fig. 4, Fig. 5). 


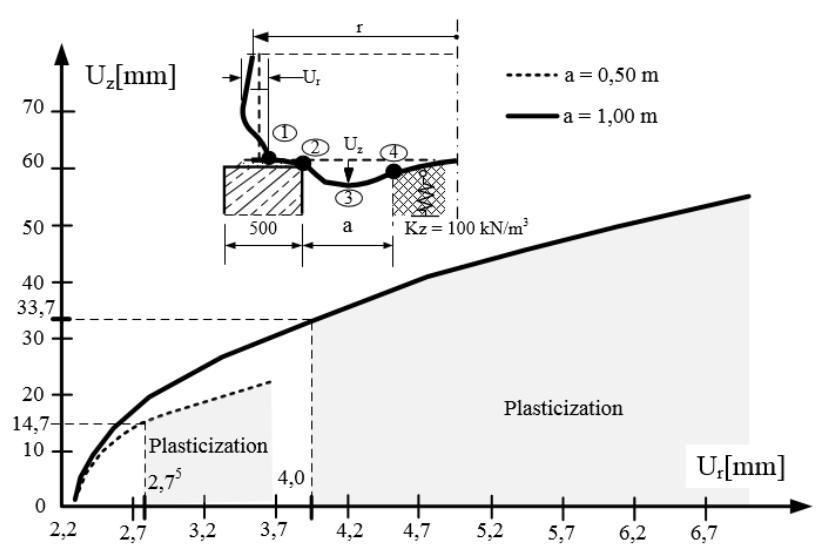

Figure 8: Elastic-plastic deformations $u_{\mathrm{r}}$ of bottom plates at the point no. 2 for different values of width widths $a$, in which there was entire loosening of soil - foundation type B.

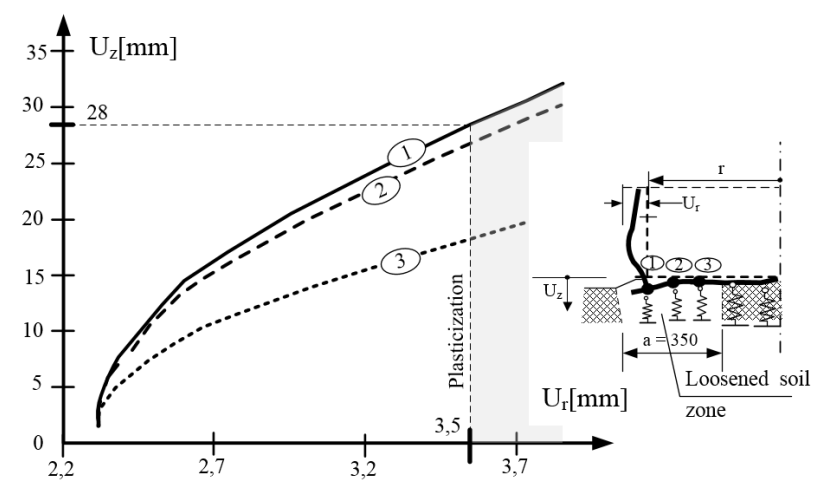

Figure 9: Elastic-plastic deformation of the bottom plate $u_{\mathrm{r}}$ at point no. 1 with significant loosening of the soil at the width $a=350 \mathrm{~mm}$ foundation type $C$.

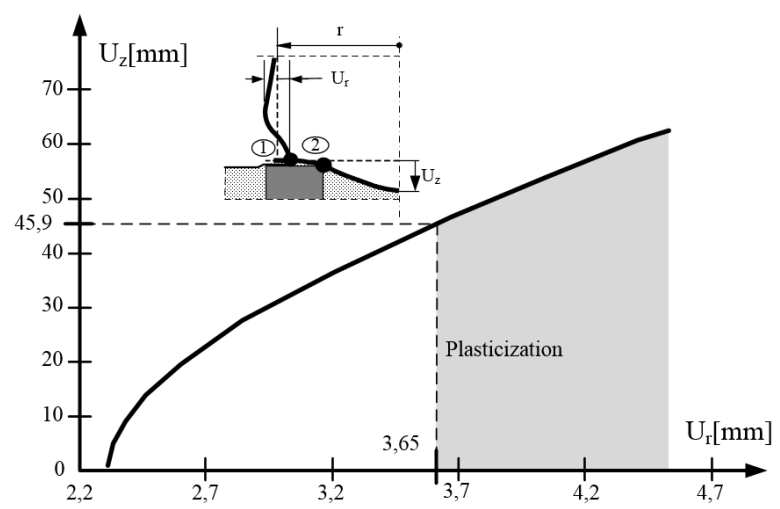

Figure 10: Elastic-plastic deformation of bottom plates $u_{r}$ at point no. 2 , when settling in the form of a trough (fig. 2a) - foundation type B.

level of the tank can be the beginning of the process of plate's cracking, which means a failure of the tank due to its leaks. Such a case is described in paper [4]. In the case of the smaller width $a$, in which there is loosening of the soil (Fig. 8), the plasticization of the bottom plate takes place at a lower value of the deformation $u_{z}=14.7 \mathrm{~mm}$.

If the analyzed tank is founded on a type $C$ foundation (Fig. 6, Fig. 9), the local settlement of the soil on the width $a=0.35 \mathrm{~m}$, resulting in vertical deformations of the bottom plates with the value of $u_{z}=28 \mathrm{~mm}$, results in plasticization of the bottom plate at point no. 1. In point no. 2 , the plasticization of the plate will occur with a slightly higher value of deformations. The process of plasticizing of the bottom plate as a result of displacements $u_{z}$ this case may also be the start of the process of cracking of the bottom plate at point 1 at the contact with the shell wall (Fig. 9) and the failure of the tank.

If a type B foundation (Fig. 1) is used in the analyzed tank with a homogeneous soil with $K_{z}$ stiffness (Fig. 7), settlement in the form of a trough (Fig. 2a) may occur after many years of operation. Numerical analyses of this case showed that the plasticization of the bottom plate will occur first of all at point no. 2 with the deformation with the value of $u_{z}=45.9 \mathrm{~mm}$ (Fig. 10). Settlement of the soil under each tank in the form of a regular trough (Fig. 2a) is unavoidable after many years of operation, even on homogeneous and well compacted soil.

Taking into account the obtained results of analyses for different cases of soil settlement and different types of the foundations, it can be concluded that the steel tanks for liquids, especially for oils and petrol, should be examined due to the values of radial deformations $u_{\mathrm{r}}$ of their shells, where there is a risk of plasticization of the bottom plates. These analyses should be carried out for the various possible soil settlements (Fig. 2) in order to be able to compare the periodical measurements of radial deformations of the lower parts of the shell with values that endanger the safe operation of tanks for flammable liquids and environmentally hazardous liquids.

If floating roofs are used in tanks for liquid fuels (gasoline, crude oil), radial deformations of the shell wall, caused by the settlement of the foundation may hinder or prevent vertical movement of such roofs, which was pointed out in paper [6]. Regular and quite simple measurements of radial deformations $u_{\mathrm{r}}$ at the lower sheets of the tank shells and analysis of their results may facilitate repair work, prevent breakdowns or eliminate disturbances in their operation. In order for the analysis of the failure risk of the tank bottom based on such measurements to have a high level of reliability, it is necessary to have the same measurement results before the start of operation of the tank, that is, after the completion of its construction. This is the only way to assess which radial deformations $u_{\mathrm{r}}$ of the shell are caused by real assembling deviations, and which are caused by settlements of the soil under the tank. 


\section{Summary and conclusions}

Settlement of soil under the bottoms of steel tanks is unavoidable and may have different forms (Fig. 2) and different reasons. Vertical deformation of the steel bottom caused by soil settlements causes additional and often high stresses in the area of direct contact between bottom plate and cylinder sheets. Very unfavorable effects of these settlements occur in tanks where a ring concrete foundation under a cylindrical shell have been used (Type B - Fig. 1). Rainwater, which sometimes flows from the tank directly under its steel bottom (Fig. 3b), may lead to the loosening of the soil and large deformations of the bottom plate, resulting even in its cracking and tank failure. ${ }^{[4]}$ Adverse effect of the use of a concrete ring foundation on the tank bottom strain during the soil settlement process is also described in [5].

In the case of quite rarely used sand foundations (Type A - Fig. 1), the types of soil settlement analyzed herein do not cause such a clear risk of a failure of the tank bottom as in the case of using ring foundations (Type B and Type $\mathrm{C}$ - Fig. 1). The greatest failure risk in such cases may occur in real life in the case of the soil settlement just next to the inner edge of the ring foundation. Measurements of radial deformation of the lower part of the cylindrical shell of the tank can be useful in assessing the value of the soil settlement and vertical deformation of the steel bottom. Due to difficulties in measuring of the steel deformation of the bottom with a filled tank, the proposed method of assessment of the stress and the range of plastic deformation of its bottom may constitute the basis for the assessment of the degree of the failure risk of the tank.

\section{References}

[1] Bąkowski T. (2017). Uneven settlement of tanks. Some issues for determination of internal forces in shell-to-bottom connection. Doctoral thesis. Department of Civil Engineering and Enviroment of Gdansk University of Technology, (in polish).

[2] Bell R. A., Junichi I. (1980). Settlement comparison used in tank - failure study. Journal of the Geotechnical Engineering Division. Proceedings of the American Society of Civil Engineers, Vo. 106. No. GT 2,1980.

[3] Weydmann G. (2011). The effect of settlement of bottom having trough shape on stress state in steel vertical cylinder tank. Doctoral thesis. Department of Civil Engineering and Enviroment of Gdansk University of Technology , (in polish)..

[4] Hotała E., Ignatowicz R. (2018). Failure risk of bottoms of cylindrical steel tanks supported on ring foundations. Building Materials, 4/2018, p. 88-90, (in polish).
[5] Wu T.Y., Liu G.R. (2000). Comparison of design methods for a tank-bottom annular plate and concrete ringwall. International Journal of Pressure Vessels and Piping, 77, p. 511-517.

[6] Lenzi M., Campana P. (2008). Ovalization of Steel Storage Tanks as a Result of Differential Settlements. Structural Engineering International, Volume 18, No. 4.

[7] EN 14015:2004. Specification for the design and manufacture of site built, vertical, cylindrical, flat-bottomed, above ground, welded, steel tanks for the storage of liquids at ambient temperature and above.

[8] SOFiSTiK 2018-9. Licence: Stalbet Wielkopolska dr inż. Rajmund Ignatowicz. 